erred), but makes us acquainted with new thoughts which in themselves are worthy of pursuit, and which in their present form are of general educational service.

\section{KARL HEUN}

The Dynamo: How Made and How Used. A Book for Amateurs. By S. R. Bottone. (London: W. Swan Sonnenschein and Co., I884.)

THIs little book of 75 pages is designed to give to amateurs practical information as to the construction of a small working dynamo-machine. What is aimed at is the building up of a machine capable of being worked by hand and suitable for experimental purposes. The dynamo-electric machine is one which an amateur mechanician may very well undertake with every prospect of success and satisfaction; and the book before us is thoroughly practical and is pleasantly written, and will, we feel sure, be acceptable to many. We are acquainted with books on the steam-engine for amateur constructors; but a dynamo of simple form is easier to make than a steam-engine, and will, we think, when made, prove a far more useful and pleasure-giving toy than a steam-engine such as an amateur can put together. When all is done, a steam-engine of amateur construction can do little more than go round and round ; but a host of experiments in electric lighting and in electro-chemistry may be made to follow on the successful completion of a small handdynamo.

The author describes the making of a very simple dynamo with a kind of shuttle-wound armature. All his instructions are clear and, as we have already said, thoroughly practical. The only question on which we have any doubt whatever is whether, at any moderate speed of turning, the dynamo will yield so much current as the reader is told he may expect.

\section{LETTERS TO THE EDITOR}

[ The Editor does not hold himself responsible for opinions expressed by his correspondents. Neither can he undertake to return, or to correspond with the writers of, rejected manuscripts. No notice is taken of anonymous communications.

[The Editor urgently requests correspondents to keep their letters as short as possible. The pressure on his space is so great that it is impossible otherwise to insure the appearance even of communications containing interesting and novel facts.]

\section{Natural Science in Schools}

As one who has been engaged in teaching science in schools for the last ten years, I should like to make some remarks on Prof. I. E. Armstrong's interesting lecture, published in NATURE of November 6 (p. 19).

(I) In the first place I would like to express my agreement with his weighty opening words. The main body of schoolmasters are so completely without any science-training that it is very difficult for many of them to see its necessity or even its advantage. The younger generation of masters in the large public schools, moreover, having come to the work in recent years have not, like their predecessors at Rugby, Clifton, Taunton, and elsewhere, had an opportunity of observing the gain of life and general intelligence which followed the introduction of science into the regular school work, in those schools where it was taken in hand seriously and with enthusiasm. Others, again, have more or less forgotten. Consequently it is still necessary to point out that, excellent as is the training given by the mathematical and classical teaching of our schools, yet that by itself it is not enough. No excellence in the method of teaching classics and mathematics will compensate for this, to adopt Dr. Armstrong's words, that they fail to develop "the faculty of observing, and reasoning from observation and experiment," that they fail to give any idea in the concrete of the nature of evidence. No doubt many able men educated on a classical or mathematical basis, can observe and reason from observation; this is, however, in spite of, and not in consequence of, their training. To the majority the deficiency is a serious matter, and probably it goes far to account for the peculiar opinions of scholars one sometimes hears expressed by practically successful men, and produces the unfortunately too prevalent idea among them that, if their sons are to go into business and to succeed, they must not stay at school too long-they must not learn too much book-learning. It should, then, in addition to its other services, be the function of science in education to keep awake and develop the natural practical intelligence of our lads, and so to make up for the deficiencies in this respect which accompany the otherwise vast advantages of a literary and mathematical culture.

(2) I suppose that no science-teacher will fail to agree with Prof. Armstrong that we have by no means exhausted the possibilities even of our present opportunities. As my object is to advocate advances, however, I will not dwell upon that part of his remarks except to say that I am sure a closer acquaintance with the methods of a good many of our science schoolmasterswith the time at their disposal, the laboratories they work in, and their boys, in short with the conditions under which they workwould satisfy him of the considerable value educationally, when it is properly done, of much that he condemns, and also that something of what he advises is already being attempted.

The lectures in schools are already, I should say, usually more or less of the nature of the tutorial classes which he recommends, and, whilst we recognise a great educational value in analytical work, if properly taught, we shall, I feel sure, be ready to ahandon that for something better as soon a: it is ready for us

Having said this much, I hasten to add that I quite recognise, on the other hand, the value of Prof. Armstrong's suggestions, and that $\mathrm{I}$ am at present conducting a class on a system which in principle is very like that which he suggests. Indeed it is in several important points the result of suggestions made to me by Prof. Armstrong some two years since. More particularly I am trying a form of what I may call the problem method of practical teaching, which Prof. Arnistrong so strongly recommends.

As it is only lately that we have had the necessary accommodation for this attempt, my experience is not very great. But I have learnt a good deal, and, as Dr. Armstrong's lecture brings the question into prominence just now, I may say what my experience is so far. Remembering that economy of time is of the first importance, and that our object in teaching science in schools is to promote a certain attitude of mind towards Nature rather than to produce skilful manipulators, I am not yet certain whether courses of work in which each pupil, with assistance, suggests and carries out the experiments himself, or tutorial classes, in which the suggestions are as far as possible elicited by the teacher from the class, and then the work is carried out by the teacher before the class, will give the best results. I tried the latter plan some years ago with beginners at 'Taunton with the most encouraging results. I believe, however, that a combination of the two methods will finally prove best. There is no doubt that greater interest is created when the pupils do the work themselves; on the other hand, much time is lost, at first, through difficulties of manipulation. Accordingly I am trying to arrange things so that the simpler experiments shall come together and be done by the boys; and when anything more difficult has to be done we fall back upon the tutorial method. I have no doubt of the advantage of practical work combined with some form of lecturing, if there is time enough. But in schools there rarely is time enough given for both. As an introduction to a course of lessons on the present system a practical course or a tutorial class on the lines proposed by Dr. Armstrong will certainly be of great value, and one or the other must, I think, be possible in almost every school.

(3) I will now pass to some points not discussed by Dr. Armstrong in which it appears to me that chemical teaching at present is open to improvement. I always aim, myself, not at informing my classes of chemical facts or principles, but, as far as possible, at leading them to discover them for themselves. In this I am more or less hampered by the absence of sufficient appreciation of the bearing of the simpler physical facts of Nature upon chemical processes. This I supply as far as I can. But I believe, and I am trying the experiment, that a real advance in the value of chemistry as an education will be made if, as an introduction, the beginners are put through a course of practical problem work which brings out in every possible way the dependence of chemical operations upon the simpler physical properties of matter; such as volatility, solubility, \&c.

(4) I was told the other day, by a great authority on educational matters, that science has had a distinct and good effect on grammar-teaching. I think, on the other hand, that scienceteachers have been rather slow to recognise and imitate one 